\title{
Applications of Conductive Polymers to Electrochemical Sensors and Energy Conversion Electrodes
}

\author{
Dong-Min Kim, Hui-Bog Noh, and Yoon-Bo Shim* \\ Department of Chemistry and Institute of Biophysio Sensor Technology (IBST), Pusan National University, Busan 609-735, \\ South Korea
}

\begin{abstract}
:
The electrical conductive polymers (ECPs) reported at my research group are introduced in this review, which works are started from the late Professor Su-Moon Park's pioneering research for polyaniline at the University of New Mexico. The electrochemical and spectroelectrochemical properties and their applications to sensor and energy conversion systems are briefly described. At first, the growth and degradation mechanism of polyaniline describes and we extend to polypyrrole, polyazulene, polydiaminonaphthalenes, and polyterthiophene derivatives. In addition, the preparation of monomer precursors having functional groups is briefly described that can give us many exceptional applications for several chemical reactions. We describe the application of these ECPs for the fabrication of chemical sensors, biosensors, biofuel cells, and solar cells.
\end{abstract}

Keywords: Electrical conductive polymer, Polymer metal complex, Electrochemical sensors, Polymer dye solar cells, Biofuel cells

Received January 9, 2014 : Accepted Febuary 3, 2014

\section{Introduction}

The ECPs have been received much attention due to their expansive potential applications, such as energy conversion materials, sensors, optical displays, and electric elements, etc.. ${ }^{1)}$ The ECPs are electroactive and participate in the electrochemical reactions, so electrochemistry has been paying a central role in characterizing ECPs. ${ }^{2}$ In addition, it is crucial to know the function and stability of ECPs for the applications to various fields. Thus, we studied the growth and degradation mechanisms of polyaniline using electrochemical (CV and impedance spectroscopy) and spectroelectrochemical (in-situ UV-Visible spectroscopy) methods. Results confirmed auto catalytic growth mechanism involved in the polyaniline growth in a sulfuric acid. ${ }^{3)}$ The detail

*Corresponding author. Tel.: 82-51-510-2244

E-mail address: ybshim@pusan.ac.kr investigation of Stillwell's previous work, ${ }^{2)}$ who was a Ph.D student of Professor Su-Moon Park; we confirmed some intermediates of nitrene, benzidine, azobenzene, phenazine, aminophenol, and benzoquinone involved in polyaniline growth and degradation processes. ${ }^{4)}$ Finally, the study has been continued to the growth and degradation mechanism of polypyrrole ${ }^{5,6)}$ and polythiophene.

Of these ECPs, polythiophene is the most stable, but it is annoying to treat thiol to form polythiophene, due to the offensive bad smell and high oxidation potential for electrochemical polymerization. To overcome this difficulty of the preparation of polythiophene, the synthesis of new monomer to easily get polythiophene has been attempted at our laboratory using the c-c coupling and the pyrrole condensation methods. The ECPs prepared from terthiophene exhibit both high environmental stability and high conductivity. In addition, they are bearing unique functional groups, which give an easy and simple route to get a specific binding with target molecules. Terthiophene 
monomeric unit functionalized on its 3'-position allows rapid polymerization, reducing a steric hindrance caused by the bulky functional group around the reaction site for polymerization. These terthiophene derivatives were applied for the preparation of sensor probe and fuel cell and solar cell active electrode materials.

\section{Electrochemical and spectroelectrochem- ical properties of conductive polymers}

The electrochemical and spectroscopic properties of ECPs provide information about their electronic properties. This is very useful for applications in batteries, electrochromic device, solar cell, and the construction of biosensor. From the last three decade, the electrochemical and spectroscopic properties of the ECPs, including poly(aniline), poly(pyrrole), poly(1,8-diaminonaphthalene), poly (1,5-diaminonaphthalene), poly (aminopyridine), poly(azulene), poly(terthiophene)-bearing metal complex, and poly(terthiophene) derivatives has been studied at our laboratory. Table 1 shows the chemical structures of ECPs. Herein, we summarized the unique properties of these ECPs.

Table 1. Structures of some conducting polymers

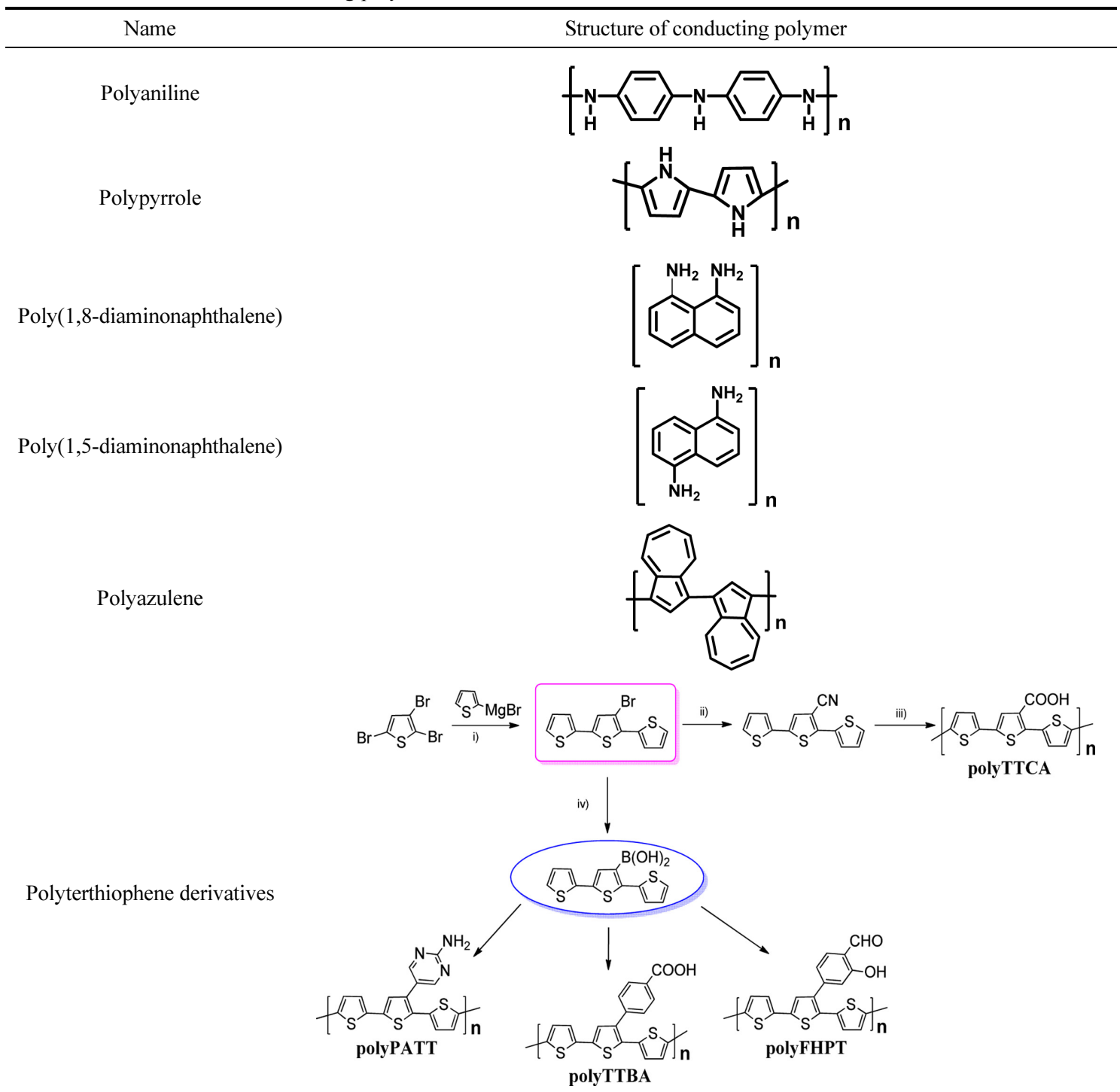




\subsection{Polyaniline}

Aniline polymer growth and its catalyst rate constant was determined using normal pulse voltammetric (NPV) techniques. The pseudo first order rate constant was $0.47 \mathrm{~s}^{-1}$ at a constant PA thickness of $140 \mathrm{~nm}^{3)}$ The earlier stage of the polymerization reaction of polyaniline has been studied employing in situ spectroelectrochemical techniques. ${ }^{4)}$ The results indicate that the nitrene cation appears to be a key intermediate species, which leads to all three possible dimers including a head-to-tail dimer (N-phenyl-p-phenylenediamine), a tail-to-tail dimer (benzidine), and a head-to-head dimer (hydrazobenzene). The oxidized forms of these dimers were all shown to be capable of growing polyaniline in the presence of aniline, even though aniline was not oxidized. The cyclic voltammetric peaks observed during the PA synthesis in the middle potential regions were shown to arise from the redox reactions of these dimers, oligomers, and degradation products of polyaniline including quinoneimines and p-benzoquinone.

\subsection{Polypyrrole}

The degradation reaction of electrochemically prepared polypyrrole has been conducted in an aqueous $1.0 \mathrm{M} \mathrm{H}_{2} \mathrm{SO}_{4}$ solution by the anodic oxidation of polymer film at platinum electrodes. ${ }^{5)}$ We concluded that the major degradation product was a mixture of maleimide and succinimide with their respective ratio of about 7:1. Kinetic measurements have been made on the degradation reaction of electrochemically prepared polypyrrole films. ${ }^{6}$ When the films are prepared at higher potentials than $1.30 \mathrm{~V}$, they are much more stable, suggesting that polymers prepared at higher electrode potentials may have different structures and/or morphology from those prepared at lower potentials.

\subsection{Poly(diaminonaphthalene)}

Electrochemically prepared poly(1,8-diaminonaphthalene) has been characterized in terms of its electrochemical, chemical, and electrical properties. ${ }^{7)}$ When the $\mathrm{Ag}^{+}$-complexed polymer is electrochemically reduced, it increases in conductivity by more than two orders of magnitude compared with that of the fully doped uncomplexed polymer by oxidation. Poly(1,8-diaminonaphthalene), has been studies employing in situ spectroelectrochemical techniques. ${ }^{8}$ The bipolar state might have been introduced when the polymer is prepared and stay in the unreduced state even after its reduction.
1,5-Diaminonaphthalene has been polymerized at glassy carbon and platinum electrodes in $0.1 \mathrm{M} \mathrm{HCL}$ and acetonitrile solutions by potential cycling methods. ${ }^{9)}$ The polymer structure, in which monomers are postulated to be linked to each other through 1- and 5- positions of naphthalene, was consistent with the infrared spectroscopic data of the polymer and coulometric data for the polymerization reaction.

\subsection{Polyaminopyridines}

Polymer-modified electrodes have been prepared by electrochemical oxidation of 2-aminopyridine and 4aminopyridine in acetonitrile and their chemical properties have been characterized. ${ }^{10)}$ The polymer films thus prepared were insulators but it was doped with $\mathrm{Ag}^{+}$or $\mathrm{Fe}(\mathrm{CN})_{4}{ }^{3-}$ to produce semiconducting films.

\subsection{Polyazulene}

Electrochemical growth of the polyazulene film and its electrochemical and spectroscopic properties were studied at platinum electrodes in acetonitrile by ac impedance and in situ spectroelectrochemical techniques. ${ }^{11)}$ During polymer growth, absorption bands were observed at 380, 480, and $680 \mathrm{~nm}$. When the polymer film was oxidized in acetonitrile after polymer fully grown, absorption bands were red shifted significantly to 580 and round $800 \mathrm{~nm}$, respectively, suggesting that the absorption bands are dependent on the chain lengths.

\subsection{Polyterthiophene-bearing metal complex}

Terthiophenes bearing pendant organomolybdenum complexes, erythro- $\left[\mathrm{Mo}_{2}\left(\eta-\mathrm{C}_{5} \mathrm{H}_{5}\right)_{2}(\mathrm{CO})_{4}\{\mu-\right.$ $\left.\eta^{2}: \eta^{2} \equiv \mathrm{C}(\mathrm{R}) \mathrm{C}\left[\mathrm{C}_{4} \mathrm{HS}\left(\mathrm{C}_{4} \mathrm{H}_{3} \mathrm{~S}-2\right)_{2}-2,5\right]\right\}(\mathrm{R}=\mathrm{H}$ 1a or $\mathrm{Ph} 1 \mathrm{~b})$ were prepared by reaction of $\left[\mathrm{Mo}_{2}(\mathrm{~h}-\right.$ $\left.\left.\mathrm{C}_{5} \mathrm{H}_{5}\right)_{2}(\mathrm{CO})_{4}\right]$ with 39-alkynyl-2,29:59,20-terthiophenes. ${ }^{12)}$ Terthiophene, to which cobalt carbonyl cluster complex is $\pi$-conjugated, $3-\left[\mathrm{CCo}_{3}(\mathrm{CO})_{9}\right]-$ 5,2:5,2-terthiophene (3-CoTTh), was prepared by reaction of 3-chloromercuro-5,2:5,2-terthiophene with $\mathrm{HCCo}_{3}(\mathrm{CO})_{9}{ }^{13)} \alpha, \omega-$ bis $\left[\mathrm{Co}_{2}(\mathrm{CO})_{6}\left\{\mu-\eta^{2}: \eta^{2}-\mathrm{C}(\mathrm{R}) \mathrm{C}\right\}\right]$ oligothiophenes derivatives, in which two dicobalt hexacarbonyl acetylides are $\pi$-conjugated onto both terminals of the oligothiophene, were prepared by the reaction of the $\alpha, \omega$-bis(alkynyl)oligothiophenes with $\mathrm{Co}_{2}(\mathrm{CO})_{8} \cdot{ }^{14)}$ The clusters 6-10 commonly exhibit three characteristic bands: a moderately intense, high-energy band, strong medium-energy band and weak-low energy band. The high-energy bands are attributed to 
the $\pi-\pi^{*}$ localized excitation. The medium- and lowenergy bands may be ascribed to the metal-to-ligand $\left(\mathrm{d}_{\mathrm{Co}}-\pi^{*}\right.$ ligand $)$ charge-transfer transitions of the cluster moiety. Terthiophene, which is the organomolybdenum oxide cluster complex is $\pi$-conjugated, erythro$\left[\left(\eta^{5}-\mathrm{C}_{5} \mathrm{H}_{5}\right)_{2} \mathrm{Mo}_{2}-(\mathrm{O})_{2}(\mu-\mathrm{O})\left\{\mu-\eta^{2}: \eta^{2}-\mathrm{C}(\mathrm{Ph})\right.\right.$ $\left.\left.\equiv \mathrm{C}\left[\mathrm{C}_{4} \mathrm{HS}\left(\mathrm{C}_{4} \mathrm{H}_{3} \mathrm{~S}-2\right)_{2}-2,5\right]\right\}\right]$ was prepared by treatment of erythro- $\left[\left(\eta^{5}-\mathrm{C}_{5} \mathrm{H}_{5}\right)_{2} \mathrm{Mo}_{2}(\mathrm{CO})_{4}\left\{\mu-\eta^{2}: \eta^{2}-\right.\right.$ $\left.\left.\mathrm{C}(\mathrm{Ph}) \mathrm{C}\left[\mathrm{C}_{4} \mathrm{HS}\left(\mathrm{C}_{4} \mathrm{H}_{3} \mathrm{~S}-2\right)_{2}-2,5\right]\right\}\right]$ with air in the presence of trimethylamine $N$-oxide in $1: 1 \mathrm{MeCN}-$ $\mathrm{CH}_{2} \mathrm{Cl}_{2} \cdot{ }^{15)}$ Such a unique electrochormism can be ascribed to the direct $\partial$-electronic interaction between the conjugated organomolybdenum cluster and the polythiophene backbone. We found that a series of newly synthesized polythiophene hybrids, $\mathrm{Poly}\left[\mathrm{Mo}_{2}(\mu-\right.$ $\left.\mathrm{C}_{5} \mathrm{H}_{5}\right)_{2}\left\{\mu-\eta 2: \eta 2-\mathrm{SC}(\mathrm{R})=\mathrm{C} \mathrm{S}\left[\mathrm{C}_{4} \mathrm{HS}\left(\mathrm{C}_{4} \mathrm{H}_{3} \mathrm{~S}-2\right)_{2}-\right.\right.$ $\left.2,5]\}_{2}\right] \mathrm{s}$ exhibit unusual electrochromism resulting probably from a synergistic interaction between the molybdenum sulfide cluster unit and the polythiophene backbone. ${ }^{16)}$

\subsection{Polyterthiophene derivatives}

5,2-5,2-Terthiophene-3-carboxylic acid (TTCA), a potentially useful starting material for the synthesis of functionalized polyterthiophenes, can be simply prepared by the treatment of 3-bromothiophene with $\mathrm{CuCN}$ in DMF followed by hydrolysis in $\mathrm{KOH}-$ ethoxyethanol (Table 1). ${ }^{17)}$ In contrast to many other ECPs, the conductivity of the resulting polymer increased even in a state of full oxidation. A ECPs was electrochemically prepared on a Pt electrode with newly synthesized 3-(4-formyl-3-hydroxyphenyl)-5,2:5,2-terthiophene (FHPT) in a $0.1 \mathrm{M}$ TBAP/ $\mathrm{CH}_{2} \mathrm{Cl}_{2}$ solution. ${ }^{18)}$ The poly[FHPT] film showed a specific catalytic response for the proton at the current media below $\mathrm{pH} 4$. It also exhibited a specific catalytic response by metal ions. Poly(ter-heteroaromatic(thiophene-pyrrole-thiophene)), PDPB, was electrochemically prepared from the 2,5-di(2-thienyl)-1H-pyrrole-1-(p-benzoic acid) (DPB) monomer using the Paal-Knorr pyrrole condensation reaction. ${ }^{19)}$ The in situ UV-visible spectroelectrochemical analysis of PDPB revealed electronic transitions at $420 \mathrm{~nm}, 654 \mathrm{~nm}$, and $870 \mathrm{~nm}$ corresponding to the $\pi-\pi^{*}$ transition, polaron, and bipolaron states, respectively. The color of the PDPB film transitioned yellow (at $0.0 \mathrm{~V}$ ) to blue (at $1.0 \mathrm{~V}$ ) when the potential was switched between the reduced and oxidized states. The electrochemical and spectroelectro- chemical properties of poly-(3,4-propylenedioxythiophene-heptyl ${ }_{2}$ ) (PProDOT-heptyl $\left.{ }_{2}\right)$ film was studied by cyclic voltammetry, in situ UV-Visible spectroscopy, and in situ conductivity measurement. ${ }^{20)}$ The redox potentials of the polaron and bipolaron states were determined by derivative cyclic voltabsorptometric (DCVA) were $+0.27 \mathrm{~V}$ and $+0.69 \mathrm{~V}$, respectively, which corresponds to the absorption bands of polaron at $760 \mathrm{~nm}$ and of bipolaron at $710 \mathrm{~nm}$.

\section{Conducting polymers in chemical sen- sors and biosensors}

ECPs are one of the most interesting materials for construction of electrochemical sensors, which covers chemical sensors, and biosensors. ECP-based electrochemical sensors have attracted much attention because of rapid detection, small size of sensor probe, high sensitivity, and selectivity for environmental monitoring and clinical diagnostics. Moreover, biomolecules can be covalently immobilized onto the ECP layers as they contain functional groups such as $-\mathrm{COOH}$, or $-\mathrm{NH}_{2}$. Thus, it is possible to control the spatial distribution of the immobilized enzymes, the film thickness, and modulation of enzyme activity. The unique properties of ECPs have been exploited for the fabrication of electrochemical sensor. We summarized the recent advances in ECPbased electrochemical sensors (potentiometric, voltammetric, amperometric) and biosensors (enzyme based biosensors, immunosensors, DNA sensors). ${ }^{21)}$

\subsection{Chemical Sensors}

Polyaniline (PA) coated on a platinum electrode was examined as a potentiometric or an optical sensor for dissolved oxygen. ${ }^{22)}$ The polymer-modified electrode behaved satisfactorily as a potentiometric sensor, its optical response (i.e., absorbance) gave a narrow linear region for varied oxygen concentrations. A detection limit of about $5 \times 10^{-7} \mathrm{~mol} / \mathrm{L}$ of dissolved oxygen was estimated for the potentiometric response. The potentiometric sensing electrode showed reasonably short response times, excellent reproducibility, and good stability.

A humidity sensor using chemically synthesized poly(1,5-diaminonaphthalene) doped with carbon has been reported. ${ }^{23)}$ The composite polymer film was prepared by mixing the poly $(1,5-\mathrm{DAN})$ powder with 
acetylene carbon black in various ratios and $6.0 \mathrm{wt} \%$ polyvinylidene fluoride in $N$-methylpyrrolidone. It is very useful to deigned miniaturized devices. A catalytic chemical polymerization of the poly(1,5-diaminonapthalene) nanofibers using Fe(III) salt as the catalyst was utilized for a water sensor for a nonaqueous solvent. ${ }^{24)}$ The linear dynamic range was from 0.05 to $20 \%$ and the detection limit was determined to be $0.01 \%$. The response of this sensor was shown to be comparable to that obtained with the Karl Fischer titration method. The performance of a poly $(1,8$ diaminonaphthalene)-modified Au electrode for the determination of the Se (IV) ion in an aqueous medium was investigated with anodic stripping voltammetry without pretreatment of the sample. ${ }^{25)}$ The detection limit employing the anodic tripping differential pulse voltammetry was $9.0 \times 10^{-9} \mathrm{M}$ for Se (IV) with $4.4 \%$ of RSD. The application of poly(Co(II)(1,8-diaminonaphthalene)) and poly(1,8-diaminonaphthalene) to the electrocatalytic reduction of molecular oxygen was investigated, which were electrochemically grown by the potential cycling method on the glassy carbon electrodes. ${ }^{26)}$ Hydrodynamic voltammetry with a rotating ring-disk electrode showed that Poly(1,8-DAN) and Poly(Co-DAN) coated electrodes converted respectively $84 \%$ and $22 \%$ of $\mathrm{O}_{2}$ to $\mathrm{H}_{2} \mathrm{O}$ via a four electron reduction pathway.

The 5,2:5,2-terthiophene-3-carboxylic acid (TTCA) monomer was modified with 1,5-diaminonaphthalene by covalent bonding, and the modified electrode was complexed with copper ions in Fig. 1. ${ }^{27)}$ The results reveal 3.6 electrons participating in the reduction of oxygen with about $75 \%$ conversion to water in an aqueous medium of $0.1 \mathrm{M} \mathrm{KNO}_{3}$. The calculated rate constant from the kinetic study on the electrocatalytic reduction of oxygen was found to be higher when compared to other copper complexes adsorbed on the carbon electrode surface. An electrochemical method to directly detect DNA hybridization was developed on the basis of a new conductive polymer, which was polymerized on the glassy carbon electrode with a TTCA in Fig 2. ${ }^{28)}$ It can be directly applied to the portable DNA sensor. An EDTA bonded conducting polymer modified electrode (EDTA-CPME) was fabricated by polymerization of 3,4-diamino-2,2:5,2-terthiophene (DATT) monomer on a GCE, followed by reaction with EDTA in the presence of catalyst. ${ }^{29)} \mathrm{Sim}$ ple immersing of the EDTA-CPME into a sample solution led to chemical deposition through the complexation with $\mathrm{Pb}^{2+}, \mathrm{Cu}^{2+}$, and $\mathrm{Hg}^{2+}$ ions, simultaneously. Analytical ability of the EDTA-CPME was demonstrated by the application for the certified standard urine reference material and tap water. A ECP was electrochemically prepared on a Pt electrode with newly synthesized 3-(4-formyl-3-hydroxy-1-phenyl)5,2:5,2-terthiophene (FHPT) in a $0.1 \mathrm{M} \mathrm{TBAP} / \mathrm{CH}_{2} \mathrm{Cl}_{2}$ solution. ${ }^{30)}$ The polymer-modified electrode exhibited a response to proton and metal ions, especially $\mathrm{Al}(\mathrm{III})$
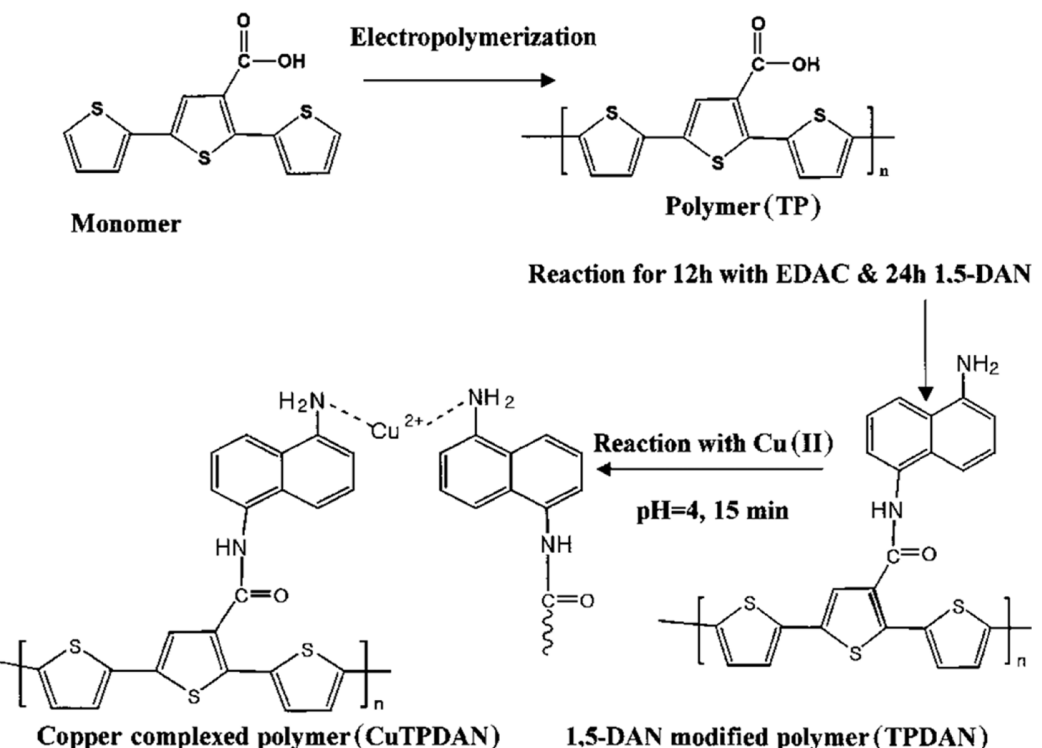

Fig. 1. Schematic representation of the modification electrodes for electrocatalytic reduction of $\mathrm{O}_{2}$. 


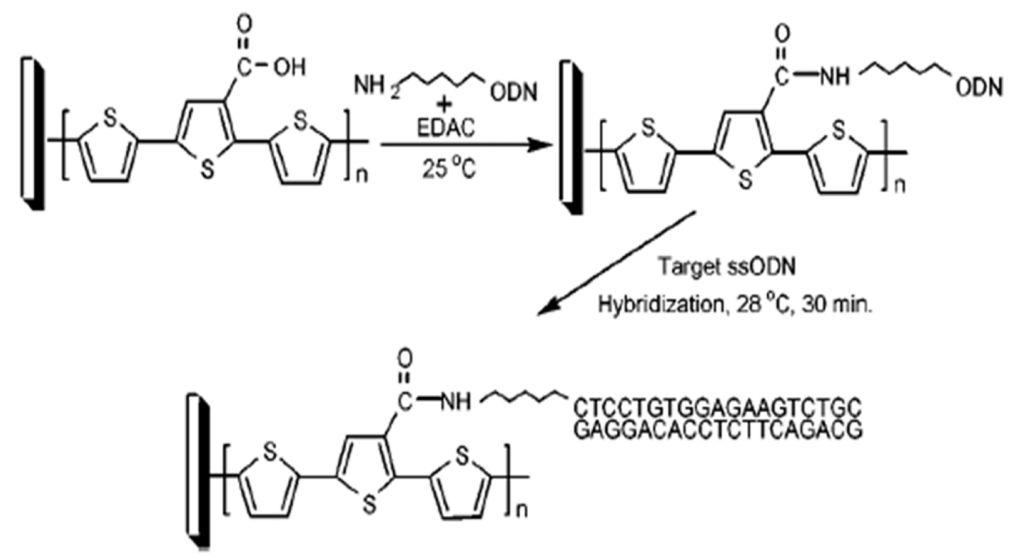

Fig. 2. Immobilization of the Probe Oligonucleotide and Hybridization for a Target Sequence.

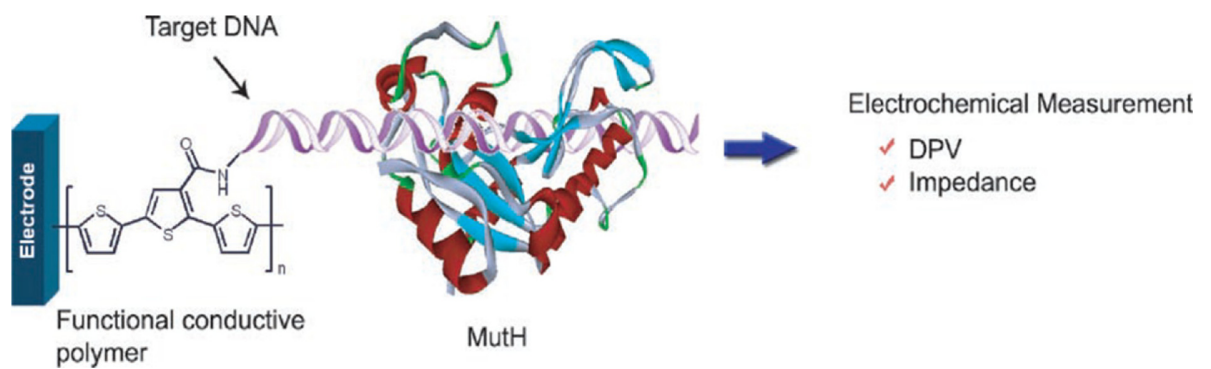

Fig. 3. Schematic representation of the experiment. The probes immobilized with ss-DNA or ds-DNA probes on the polyTTCA film-coated electrode were reacted with the different concentrations of both proteins, MutH (Protein Data Bank code $2 \mathrm{AZO}$ ) and mPurb, for the electrochemical analysis.

ions. This analytical method was successfully verified for the analysis of trace amounts of $\mathrm{Al}(\mathrm{III})$ ions in a human urine sample.

\subsection{Biosensors using pure ECPs}

A disposable immunosensor based on a polyTTCA coated screen-printed carbon electrode has been developed for the detection of rabbit IgG. ${ }^{31)}$ This sensor was based on the competitive assay between free and labeled antigen for the available binding sites of antibody. A impedimetric and amperometric immunosensor for the determination of carp (Carassius auratus) vitellogenin (Vtg), a female-specific protein, has been proposed based on an antibody-captured ECP coated electrode. ${ }^{32,33)}$ The sensor showed high selectivity and sensitive response to Vtg and has applied to the determination of Vtg in real male (and female) carp and fish serum samples. Label-free detection of bisphenol A based on the impedance measurement was achieved with an impedimetric immunosensor. ${ }^{34)}$ The immunosensor showed spe- cific recognition of BPA with less interference than $4.5 \%$ from other common phenolic compounds. To develop a general method for the detection of histidine-tagged proteins, the interactions of the histidine epitope tag of MutH and MutL proteins with the epitope specific monoclonal anti-His6 antibody were monitored by a label-free direct method using impedance spectroscopy. ${ }^{35)}$ The specificity of the sensor was demonstrated by showing that no impedance change was occurred when the sensor was exposed to both of non-tagged MutH and MutL proteins.

Direct electron transfer process of immobilized horseradish peroxidase (HRP) on a polyTTCA film, and its application as a biosensor for $\mathrm{H}_{2} \mathrm{O}_{2}$, were investigated by using electrochemical methods. ${ }^{36)}$ The HRP/polyTTCA modified electrode acted as a sensor and displayed an excellent specific electrocatalytic response to the reduction of $\mathrm{H}_{2} \mathrm{O}_{2}$. Amperometric choline biosensors were fabricated by the covalent immobilization of choline oxidase $(\mathrm{ChO})$ and $\mathrm{ChO} / \mathrm{HRP}$ onto polyTTCA modified elec- 
trodes. ${ }^{37)}$ A sensor modified with $\mathrm{ChO}$ utilized the oxidation process of enzymatically generated $\mathrm{H}_{2} \mathrm{O}_{2}$ in a choline solution at $+0.6 \mathrm{~V}$. Results showed good selectivity to interfering species. The potential use of hydrazine sulfate was examined for the catalytic reduction of enzymatically generated $\mathrm{H}_{2} \mathrm{O}_{2}$ in a biosensor system. ${ }^{38)}$ The performance of the hydrazinebased sensor was compared with an HRP-based glucose sensor as a model of a biosensor. The proposed glucose sensor was successfully applied to human whole blood and urine samples for the detection of glucose. As shown in Fig 3, a simple, direct method for the detection of DNA-protein interaction was developed with electrochemical methods. ${ }^{39)}$ Impedance spectroscopy and differential pulse voltammetry (DPV) distinguished the interaction between the DNA probes with mouse Purb (mPurb), ss-DNA binding protein, and with Escherichia coli MutH, a ds-DNA binding protein.

Cytochrome c (cyt c)-immobilized monolayers and multiple monolayers of a polyTTCA were prepared. Monolayer of monomer precursor was fabricated with the Langmuir-Blogett technique. ${ }^{40)}$ The immobilization of cyt $\mathrm{c}$ on the polymer layer reveals the direct electron-transfer processes of cyt $\mathrm{c}$. Cyt $\mathrm{c}$ bonded on the conductive polymer layers was applied for bioelectronic devices with unique functionality. Model biomembranes composed of polyDATT/DGS/POPA and polyDATT/DGS/CL were separately prepared on gold electrodes. ${ }^{41)}$ Cyt $c$ was immobilized onto these model biomembranes through the charge interaction. The applicability of these cyt $c$ immobilized bioimitation membranes as the biosensors was tested in the determination of superoxide. An enzymatic biosensor was fabricated by the covalent immobilization of pyruvate oxidase (PyO) onto the nano-particle comprised polyTTCA (nano-CP) layers on a GCE for the amperometric detection of the phosphate ions. ${ }^{42)}$ The electrochemically prepared nano-CP lowered the oxidation potential $(+0.40 \mathrm{~V}$ versus $\mathrm{Ag} / \mathrm{AgCl})$ of an enzymatically generated $\mathrm{H}_{2} \mathrm{O}_{2}$ by $\mathrm{PyO}$ in a phosphate solution. A biosensor based on cytochrome $c 3$ (cyt $c 3$ ) immobilized onto a ECP has been introduced to detect and quantify superoxide radical $\left(\mathrm{O}^{{ }^{-}}\right){ }^{43)}$ A potential application of the cyt $c 3$ modified electrode was evaluated by monitoring the bioelectrocatalytic response towards the $\mathrm{O}^{\circ-}$.

A nitric oxide (NO) microbiosensor based on cyt $c$ immobilized onto a polyTTCA layer has been fabri- cated for the in vivo measurement of NO release stimulated by cocaine abuse. ${ }^{44)}$ The microbiosensor was applied into the rat brain to test fluctuation of $\mathrm{NO}$ evoked by the abuse drug cocaine. A needle-type amperometric glutamate microbiosensor based on the covalent immobilization of glutamate oxidase (GlOx) onto the polyTTCA layer was fabricated for in vivo measurements. ${ }^{45)}$ The proposed glutamate microbiosensor was successfully used for in vivo monitoring of the extracellular glutamate released by cocaine stimulation. A xanthine biosensor was fabricated by covalent immobilization of xanthine oxidase (XO) onto a polyTTCA. ${ }^{46)}$ The biosensor efficiently detected xanthine through oxidation at $+0.35 \mathrm{~V}$ and reduction at $0.25 \mathrm{~V}$ (versus $\mathrm{Ag} / \mathrm{AgCl}$ ) of enzymatically generated hydrogen peroxide. The applicability of the biosensor was tested by detecting xanthine in blood serum and urine real samples. A selective detection method for dopamine (DA) was developed by incorporating cibacron blue (F3GA) into poly-1,5-diaminonaphthalene (PDAN) layer. ${ }^{47)}$ This sensor showed rapid, excellent selectivity, and stable amperometric response. Direct electrochemistry of cholesterol oxidase (ChOx) immobilized on the PDATT was achieved and used to create a cholesterol biosensor. ${ }^{48)} \mathrm{MP}$ co-immobilized with ChOx on the AuNPs-GSH/polyDATT exhibited an excellent amperometric response to cholesterol. 3Aminophenyl boronic acid (APBA) bonded on the polyTTCA layer was prepared and used for detection of saccharides through the complexation between boronic acid and diol groups of saccharide. ${ }^{49)}$ The proposed sensor was applied for the detection of other saccharides including galactose and mannose. A simple detection method of ascorbic acid (AA) through selective catalytic oxidation has been developed using a poly-3-(2-aminopyrimidyl)-2,2:5,2-terthiophene (pA PTT) ${ }^{50)}$ This method proved to be effective in the determination of AA in the presence of various biological interfering species.

A simple and fast method for electrochemical detection of amplified fragments by PCR was successfully developed using $\mathrm{CE}$ in a microfluidic device with a polyTTCA modified screen-printed carbon electrode (SPCE). ${ }^{51)}$ DNA fragments amplified by PCR were separated within $210 \mathrm{~s}$ in a $75.5 \mathrm{~mm}$-long coated-separation channel at a separation field strength of $-200 \mathrm{~V} /$ $\mathrm{cm}$. The analysis procedure was simplified and rendered reproducible by using $0.50 \% \mathrm{w} / \mathrm{v}$ hydroxyethylcellulose as a separation matrix in a coated channel. 
An electrochemical method was developed for analyzing PCR amplification through the detection of inorganic phosphates (Pi). ${ }^{52)}$ This method coupled a microchip to a nanoparticle comprising polyTTCA/ pyruvate oxidase (PyO) modified microbiosensor. On the microbiosensor surface, pyruvate was converted to $\mathrm{H}_{2} \mathrm{O}_{2}$ by $\mathrm{PyO}$ in the presence of $\mathrm{Pi}$ and oxygen, and subsequently, the anodic current of enzymatically generated $\mathrm{H}_{2} \mathrm{O}_{2}$ was detected.

\subsection{Biosensors using ECPs-metal complex}

The hydrogen transfer reaction was investigated using novel $\mathrm{Ru}$ (II) complexes. ${ }^{53)}$ This report examining the effectiveness of the catalysts employed acetophenone as the benchmark substrate. Complexation of $\mathrm{Cu}$ ions in a polyTTCA film resulted an enhanced anodic current for acetaminophen oxidation when compared to polymer coated and bare glassy carbon electrodes in human blood and buffer media. ${ }^{54)}$ The analytical utility of the modified electrode was achieved by analyzing the content of acetaminophen in different drugs without pretreatment using $\mathrm{CV}$ and amperometric techniques.

An amperometric bilirubin biosensor was fabricated by complexation the $\mathrm{Mn}$ (II) ion with a polyTTCA and the final biosensor surface was coated with a thin polyethyleneimine (PEI) film containing an enzyme, ascorbate oxidase (AsOx). ${ }^{55)}$ The bilirubin sensor exhibited good stability and fast response time $(<5 \mathrm{~s})$. The applicability of this bilirubin sensor was tested in a human serum sample. A peroxynitrite (ONOO-) biosensor has been developed through the preparation of a new manganese-[poly-2,5-di-(2-thienyl)-1H-pyrrole)-1-(p-benzoicacid)] complex. ${ }^{56)}$ The complex selectively enhanced the reduction process of $\mathrm{ONOO}^{-}$which was used as the analytical signal for chronoamperometric detection.

A new electron-transfer mediator, 5-[2,5di(thiophen-2-yl)-1H-pyrrol-1-yl]-1,10-phenanthroline iron(III) chloride (FePhenTPy) was synthesized through a PaalKnorr condensation reaction. ${ }^{57)} \mathrm{A}$ disposable amperometric glucose sensor with NADGDH was constructed with FePhenTPy as an electron-transfer mediator on a screen printed carbon electrode (SPCE), where the addition of reduces graphene oxide (RGO) to the mediator showed the enhanced sensor performance. The reliability of proposed glucose sensors was evaluated by the determination of glucose in artificial blood and human blood samples.

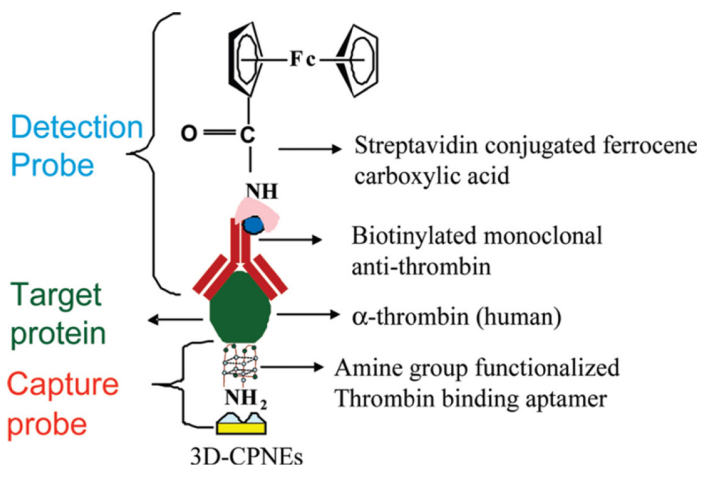

Fig. 4. The schematic representation of the fabrication of the Apt/3D-CPNEs-based thrombin aptamer sensor.

\subsection{Biosensors using ECPs composite}

Figure 4 represents the Au nanoparticles-doped conducting polymer nanorods. These electrodes (AuNPs/CPNEs) were prepared by coating Au nanorods (AuNRs) with a polyTTCA layer. ${ }^{58)}$ The AuNPs/CPNEs combining catalytic activity of ferrocene to ascorbic acid were used for the fabrication of an ultrasensitive aptamer sensor for thrombin detection. The selectivity and stability of the proposed thrombin aptamer sensor were excellent, and it was tested in a real human serum sample for the detection of spiked concentration of thrombin. An ultrasensitive electrochemical immunosensor for a protein using a $\mathrm{Ag}(\mathrm{I})$-cysteamine complex (Ag-Cys) as a label was fabricated. ${ }^{59)}$ The target protein, IgG was sandwiched between the anti-IgG antibody that covalently attached onto the polyTTCA layer and AuNPs-anti-IgG. Using square wave voltammetry, well defined Ag stripping voltammograms were obtained for the each target concentration. An amperometric chloramphenicol (CAP) immunosensor was fabricated by covalently immobilizing anti-chloramphenicol acetyl transferase (anti-CAT) antibody on cadmium sulfide nanoparticles (CdS) modified-dendrimer that was bonded to the polyTTCA layer. ${ }^{60}$ The AuNPs, dendrimers, and CdS nanoparticles were deposited onto the polymer layer in order to enhance the sensitivity of the sensor probes. The amperometric immunosensor has demonstrated the toxicity of endocrine disrupters (EDs) through monitoring the in vitro i-NOS concentration change, where the antibody of inducible nitric oxide synthase (i-NOS) was immobilized on the ECP-gold nanoparticles composite. ${ }^{61)}$ A novel amperometric immunosensor with an enhanced sensitivity for the detection of neomycin (Neo) was prepared by covalently immobilizing a 
monoclonal Neo antibody onto a poly-[2,5-di-(2thienyl)-1H-pyrrole-1-(p-benzoic acid)] (polyDPB) ${ }^{62)}$ The probe was used to detect Neo in a sandwich-type approach, where the secondary antibody was attached to gold nanoparticle-decorated multiwall carbon nanotubes labeled with hydrazine (HydMWCNT(AuNP)-Ab2). An amperometric immunosensor for IgG was developed by covalently immobilizing anti-IgG on multiwall carbon nanotubeembedded polyTTCA ${ }^{63)}$ Hydrazine was used as a catalyst for the reduction of $\mathrm{H}_{2} \mathrm{O}_{2}$. The proposed immunosensor was evaluated for clinical applications in a rabbit serum sample.

We identified versatile single-strand DNA aptamers for Plasmodium lactate dehydrogenase (pLDH), a biomarker for malaria, via the Systematic Evolution of Ligands by Exponential enrichment (SELEX). ${ }^{64)}$ The pLDH aptamers selectively bound to the target proteins with high sensitivity $(\mathrm{Kd}=16.8-49.6 \mathrm{nM})$. Highly sensitive label-free detection of kanamycin is achieved with a DNA aptamer sensor based on a polyDPB/gold self-assembled nanocomposite. ${ }^{65)}$ The probe is applied to detect kanamycin by using voltammetric techniques. To simultaneous evaluation of the binding affinity of a series of aptamers toward a target molecule, the electrochemical microarray chip was modified by immobilizing seven aptamers obtained from the SELEX process and a control sequence onto gold nanoparticle-comprised ECPcoated microarray electrodes. ${ }^{66}$ ) The electrochemical response of the captured kanamycin was studied to evaluate the binding affinity of the aptamers, which showed the same trend with the fluorescence spectroscopic results.

An electrochemical immunosensor for the detection of HER2-overexpressing breast cancer cells was fabricated by covalently immobilizing anti-HER2 onto a nanocomposite layer that was composed of self-assembled DPB on AuNPs. ${ }^{67)}$ This method exhibited an excellent diagnosis method for the detection of SK-BR-3 breast cancer cells. A highly sensitive and selective sensor for daunomycin was developed using phosphatidylserine (PS) and aptamer as bioreceptors. ${ }^{68)}$ The PS and aptamer were co-immobilized onto AuNPs/polyTTBA. Direct electrochemistry of daunomycin was used to fabricate a label free sensor that monitors current at $0.61 \mathrm{~V}$. Interaction between the sensor probe and daunomycin was determined with DPV. An amperometric immunosensor was fabricated for the detection of osteoproteogerin (OPG) by covalently immobilizing a monoclonal OPG antibody (anti-OPG) onto the gold nanoparticles (AuNPs) deposited functionalized polyTTCA. ${ }^{69)}$ The principle of immunosensor was based on a competitive immunoassay between freeOPG and labeled-OPG for the active sites of antiOPG. Amperometric immunosensors were developed to diagnose lung cancer through the detection of Annexin II and MUC5AC. ${ }^{70)}$

Novel nanostructures of gold nanoparticle (AuNP) encapsulated-2,2:5,5-terthiophene-3-benzoic acid (TTBA) have been developed to study biosensor probe materials. ${ }^{71)}$ This study looked at the applicability of the self-assembled TTBA layer where the results indicated an efficient electrochemical response toward nitric oxide synthase (i-NOS). Biomimetic layers triggering the redox process of cyt $\mathrm{c}$ by $\beta$-nicotinamide adenine dinucleotide (NADH) were fabricated and applied for the detection of NADH. ${ }^{72)}$ A probe was constructed based on a polyTTCA formed on the Au nanoparticles; the probe was modified with biomaterials including cyt c, lipids, and ubiquinone, which are involved in electron transfer sequence in the cell membrane. The electron transfer process triggered by the presence of NADH was used to determine the NADH concentration. A highly selective nitric oxide (NO) biosensor was developed by immobilizing microperoxidase onto the MWCNT-polyTTCA nanocomposite. ${ }^{73)}$ Catalase and superoxide dismutase co-immobilized on the probe successfully protected the interferences of $\mathrm{H}_{2} \mathrm{O}_{2}$ and $\mathrm{O}_{2}$ during $\mathrm{NO}$ detection.

A highly sensitive in vivo biosensor for glutathione disulfide (GSSG) is developed using covalently immobilized-glutathione reductase (GR) and $\beta$-nicotinamide adenine dinucleotide phosphate (NADPH) on gold nanoparticles deposited on polyTTBA. ${ }^{74)}$ The results obtained are reliable, implying a promising approach for a GSSG biosensor in clinical diagnostics and oxidative stress monitoring. Enhanced stability and sensitivity of a superoxide anion radical $\left(\mathrm{O}_{2}{ }^{--}\right)$microbiosensor were achieved through the sequential immobilization of lipid and Cyt $\mathrm{c}$ covalently bonded onto a ECP layer in Fig. $5 .{ }^{75)}$ The in vivo microbiosensor implanted into rat brain successfully determined the extracellular level of $\mathrm{O}_{2}{ }^{--}$.

A highly sensitive and selective method is developed for the simultaneous detection of dopamine and 
(A)

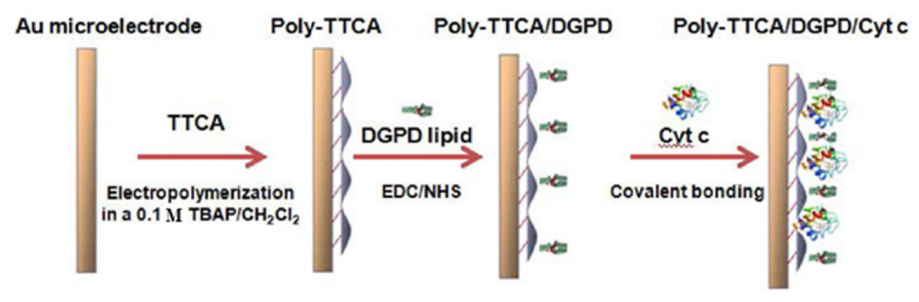

(B)
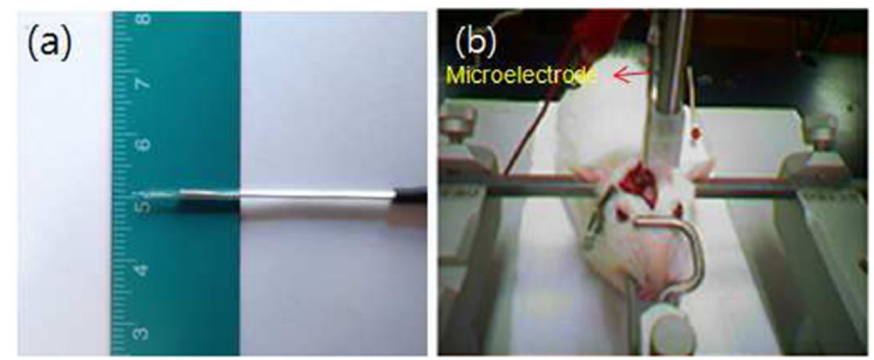

Fig. 5. (A) Schematic illustration of a polyTTCA/DGPD/Cyt c based $\mathrm{O}_{2}{ }^{-}$microbiosensor and the design of an $\mathrm{Au}$ microelectrode $(100 \mu \mathrm{m})$. (B-a) Photograph of a microelectrode and (B-b) the placement of a microelectrode in a rat's brain during in vivo experiment.

acetaminophen by reactive blue-4 dye entrapped poly-1,5-diaminonaphthalne (polyDAN) composite film layer. ${ }^{76)}$ The interaction between an anticancer drug (daunomycin) and cancer cell membrane components has been studied using an aptamer probe immobilized on a ECP-gold nanoparticle composite film through electrochemical and fluorescence methods and applied to the quantitative detection of cancer cells. ${ }^{77)}$ A sensitive electrochemical assay of DNA and proteins employing electrocatalytic reduction of $\mathrm{H}_{2} \mathrm{O}_{2}$ by labeled hydrazine on the probe immobilized surfaces was developed. ${ }^{78)}$ The method utilizes a polyTTCA covalently linked to the dendrimer (DEN) and hydrazine. The method eliminates the use of enzymes for DNA and protein detection and opens a way for DNA-free detection of proteins. We have developed electrochemical DNA and protein sensors on screen-printed electrodes based on the catalytic activity of hydrazine. ${ }^{79)}$ The sensors use polyTTCA to make firm immobilization of DEN. Avidin-labeled hydrazine (Av-Hyd) was then immobilized on the sensor surfaces between the Av-Hyd unit and the biotinylated DNA or secondary antibody.

The direct electrochemistry of laccase was promoted by Au nanoparticle (AuNP)-encapsulated DEN onto a polyDATT, which was applied for the detection of catechin. ${ }^{80}$ ) A catechin biosensor based on the electrocatalytic process by direct electrochem- istry of laccase was developed. An amperometric lactate biosensor was developed based on a polyTTCA and multiwall carbon nanotube (MWNT) composite on a gold electrode ${ }^{81)}$ Lactate dehydrogenase (LDH) and the oxidized form of nicotinamide adenine dinucleotide $\left(\mathrm{NAD}^{+}\right)$were subsequently immobilized onto the pTTCA/MWNT composite film. The results showed that the sensitivity, stability, and reproducibility of the sensor improved significantly using polyTTCA/MWNT composite film. The performance of an enzyme sensor fabricated through covalent bond formation on the HRP-bonded polyDAN layer with AuNPs was applied to catalyze the electrochemical reduction of $\mathrm{H}_{2} \mathrm{O}_{2}{ }^{82)}$ We reported the development of a disposable amperometric $\mathrm{HbA}_{1 \mathrm{C}}$ sensor for the finger prick blood test through a simple treatment of a drop of blood ${ }^{83)}$ To fabricate the sensor probe, the polyTTBA was electrochemically grown onto the AuNPs coatedscreen printing electrode, followed by the covalent attachment of aminophenyl boronic acid to polyTTBA. The reliability of the proposed $\mathrm{HbA}_{1 \mathrm{C}}$ sensor was evaluated through the comparison of the results among the conventional method.

\subsection{Application of sensors to separation analysis}

As shown in Fig. 6, a simple and highly sensitive method for simultaneous detection of anticancer drugs is developed by integrating the preconcentra- 


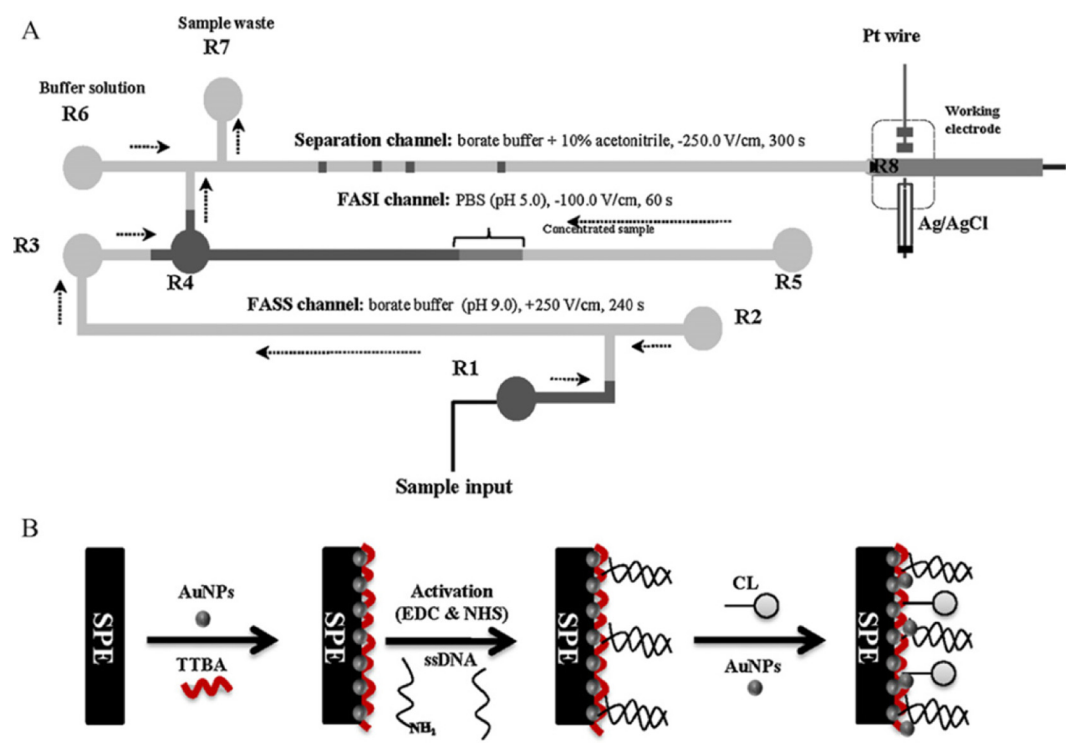

Fig. 6. (A) Schematic diagram of the microfluidic device. (B) Schematic representation of the biosensor fabrication.

tion and separation steps in a microfluidic device with an amperometric biosensor. ${ }^{84)}$ An amperometric detection with ds-DNA and cardiolipin modified screen printed electrodes are used for the detection of anticancer drugs at the end of separation channel. A highly sensitive and robust method for simultaneous detection of five sulfonamide drugs is developed by integrating the preconcentration and separation steps in a microfluidic device. ${ }^{85)}$ An amperometry is performed for the selective detection of sulfonamides using an $\mathrm{Al}_{2} \mathrm{O}_{3}$-AuNPs modified carbon paste electrode at the end of separation channel. The applicability of the method to the direct analysis of sulfonamides in real meat samples is successfully demonstrated.

\section{Conductive polymers in solar cells and fuel cell}

Silicon-based solar cells are commercially available due to their high solar-to-electric energy conversion efficiency. However, several disadvantages, such as, heavy weight, high cost, and lack of flexibility necessitated the development of organic photovoltaic cells and dye-sensitized solar cells (DSSCs). ${ }^{86)}$ DSSCs have a maximum energy conversion efficiency of $\sim 10 \%$ using ruthenium complex dye. The ruthenium complex dyes are also associated with disadvantages including high cost, lack of long-term sta- bility and environmental safety. Recently, the interest in ECPs, such as poly(p-phenylene vinylene)s and poly(thiophene)s etc., have been studied as metalfree organic sensitizer for DSSCs. Especially, poly(terthiopnene)s are attractive as sensitizers in DSSCs because the heteroaromatic and extended $\pi$ conjugated backbone structure provide high environmental stability, electrical conductivity, and other attractive physical properties and it is a possible alternative material to the Ruthenium complexes. Thus, we have studied its performance as a polymer dye sensitizer for DSSCs using various functional groups bonded poly(terthiophene)s derivative.

ECP precursors, including carboxylic acid, cyano groups, amino groups, TTCA, 3-cyano-5,2-5,2-terthiophene (CTT), and DATT are synthesized in our laboratory. ECP layers were formed on the $\mathrm{TiO}_{2}$ electrode by electropolymerization of the monomers in a $0.1 \mathrm{M} \mathrm{TBAP} / \mathrm{CH}_{2} \mathrm{Cl}_{2}$ solution using the potential cycling method. The band gap energies of polyTTCA, polyCTT, and polyDATT are similar in the range of $1.93-2.10 \mathrm{eV}$. Of these, the energy conversion efficiency of polyTTCA on the $\mathrm{TiO}_{2}$ solar cell is the higher at $2.32 \%$ than that of polyCTT and polyDATT. ${ }^{87)}$ Because, the anchoring group, - $\mathrm{COOH}$ enhances the adsorption of the dye onto the $\mathrm{TiO}_{2}$ layer effectively and strongly through the formation of C-O-Ti bonds, which improve the transfer of the electrons from polyTTCA to $\mathrm{TiO}_{2}$. 


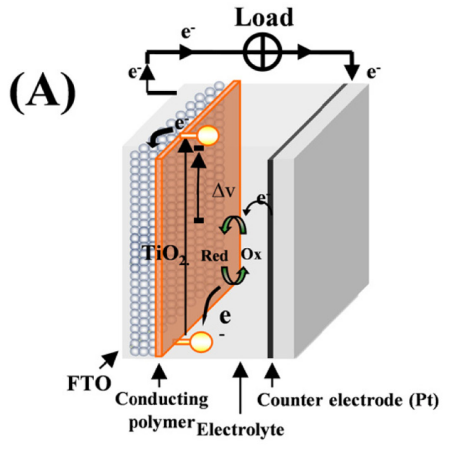

(a)

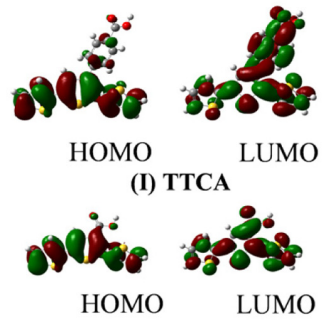

(II) TTCA

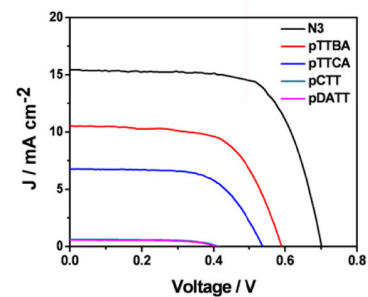

(c)

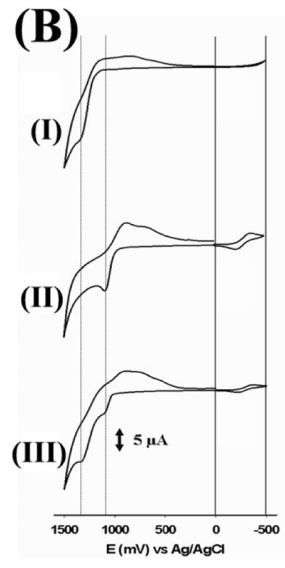

(a)

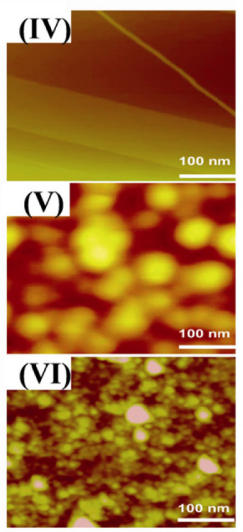

(b)

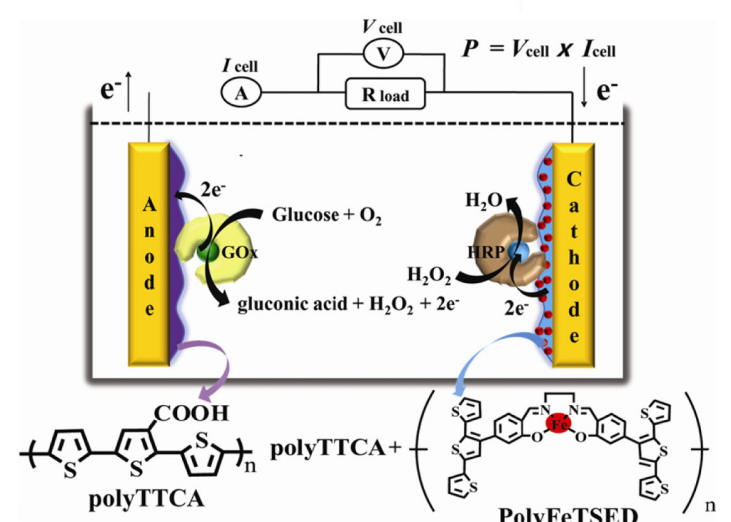

(b)

Fig. 7. (A-a) Schematic diagram of the polymer dye solar cell. (A-b) Frontier molecular orbital of the HOMO and LUMO levels of (I) TTBA and (II) TTCA. (A-c) The J-V characterization of N3 dye (reference material), polyTTBA, polyTTCA, polyCTT, and polyDATT as a sensitizer on $\mathrm{TiO}_{2}$ solar cell under AM 1.5 condition (active layer $=0.24 \mathrm{~cm}^{2}$ ). (B-a) CVs for electropolymerization using (I) TTCA, (II) FeTSED, and (III) TTCA + FeTSED (1:1 mole ratio) monomers. AFM images for (IV) bare, (V) polyTTCA, and (VI) poly(TTCA-FeTSED) coated on the highly ordered pyrolytic graphite electrodes. (B-b) Schematic diagram of a biofuel cell with a conducting polymer catalyst.

Recently, polyTTBA has been synthesized by introduction of a benzene ring at the para position into terthipnene backbone to improve the low energy conversion efficiency of the polymer dye solar cells. From the density functional theory (DFT) calculation, the LUMO orbital of the TTBA shows a higher electron density distribution than the TTCA without a benzene ring in Fig. 7(A-b). Hence, the TTCA units can do more effective electron injection from the LUMO level to the $\mathrm{TiO}_{2}$ conduction band in comparison to the TTCA. The best energy conversion efficiency of polyTTBA solar cell is $3.97 \%$ (Fig. 7(Ac)), which is 1.7 times higher than that of polyTTCA without a benzene ring in the structure. ${ }^{88)}$ This means that the modification of the polymer structure can be efficient for the electron transfer with small steric hinderance and enhanced conjugation structure. Additionally, the other polyterthiophene derivative and oligothiophenes subsitituted with donor/acceptor groups have been extensively investigated ${ }^{89,90)} \mathrm{We}$ believe that the modified terthiophene monomer structure would lead to a more effective use of ECPs in photovoltaic cells.

Conventional fuel cells use metals like platinum and nickel as catalysts, whereas, the enzymatic biofuel cells use enzymes obtained from living cells. 
However, the primary requirement is that the enzymes which allow the fuel cell to operate must be stably immobilized as the anode and cathode. Our laboratory utilized polyTTCA and polyFe(III)-[N,N'-bis[4$(5,2$ ':5',2"'-terthien-3'-yl)salicyliden]-1,2-ethanediamine] (polyFeTSED) which were electrochemically polymerized on an Au surface for use, as mediators and catalysts for a biofuel cell (Fig. 7(B-a)). ${ }^{91)}$ The glucose oxidase (GOx) or horseradish peroxidase (HRP) were immobilized onto the polyTTCA layer through covalent bond formation, which allowed the direct electron transfer processes of the enzymes. The anode with immobilized GOx and the cathode with immobilized HRP were used as model enzyme systems in biofuel cells for glucose and $\mathrm{H}_{2} \mathrm{O}_{2}$ detection, respectively (Fig. 7(B-b)). The copolymer of polyFeTSED complex with polyTTCA revealed a catalytic activity for the electrochemical reduction of $\mathrm{H}_{2} \mathrm{O}_{2}$ and resulted in approximately a seven fold increase in the power density of the biofuel cell over that of polyTTCA itself. Moreover, the conjugated polymers extended the lifetime of biofuel cell to 4 months through the stabilization of immobilized enzymes. The biofuel cell operated in a solution containing glucose and anode-produced $\mathrm{H}_{2} \mathrm{O}_{2}$ generated an open-circuit voltage of approximately $366.0 \mathrm{mV}$, while the maximum electrical power density extracted from the cell was $5.12 \mu \mathrm{W} \mathrm{cm}$ c $^{-2}$ at an external optimal load of $25.0 \mathrm{k} \Omega$. The biofuel cell electrodes fabricated in this study had a wide range of potential applications as substrates for various potential bio and chemical sensors and bio-devices.

\section{Conclusion}

The ECPs are very useful materials in electrochemical sensor probe substrate that immobilize sensing probe molecules, due to the own conductivity and easy modification of functional group. In addition, modification of the monomer precursor with a functional group having catalytic property to a specific reaction, such as the oxygen reduction reaction, could be led to apply for the nonmetallic electrode materials for fuel cells. One of other unique chemical and physical properties responding to photons could be used as the polymer dyes in solar cells.

\section{Acknowledgments}

This work was financially supported by the National Research Foundation of Korea (Grant No.
20100029128). Especially, I very appreciate the organizers and participants of the Su-Moon Park Memorial Symposium held at the Autumn Meeting of the Korean Electrochemical Society.

\section{References}

1. T.A. Skotheim, R. Lelsenbaumer, J.R. Reynolds (Eds.), Hand Book of Conducting Polymers, Conjugated Polymers: Processing and Applications, 3rd Ed., CRS press, (2006).

2. S.-M. Park, Electrochemistry of $\pi$-Conjugated Polymer. In: H. S. Nalwa (Ed.), Handbook of Organic Conductive Molecules and Polymers, vol. 3, Wiley, Chichester, (1997).

3. Y.-B. Shim and S.-M. Park, Synthetic. Met., 29, E169 (1989).

4. Y.-B. Shim, M.-S. Won, and S.-M. Park, J. Electrochem. Soc., 137, 538 (1990).

5. D.-S. Park, and Y.-B. Shim, S.-M. Park, J. Electrochern. Soc., 140, 609 (1993).

6. D.-S. Park, Y.-B. Shim, and S. -M. Park, J. Electrochem. Soc., 140, 2749 (1993)

7. J.-W. Lee, D.-S. Park, and Y.-B. Shim, S.-M. Park, J. Electrochem. Soc., 139, 3507 (1992).

8. M. Ruan, S.-M. Park, and Y.-B. Shim, Proceedingselectrochemical society, PV; 94-4, 269 (1994).

9. C.-S. Jin, Y.-B. Shim, and S.-M. Park, Synthetic. Met., 69, 561 (1995).

10. D.-S. Park, Y.-B. Shim, and S.-M. Park, Electroanal., 8, 44, (1996).

11. Y.-B. Shim and S.-M. Park, J. Electrochem. Soc., 144, 3027 (1997)

12. D.H. Kim, B.S. Kang, S.M. Lim, K.-M. Bark, B.G. Kim, M. Shiro, Y.-B. Shim, and S.C. Shin, J. Chem. Soc., Dalton Trans., 1998, 1893 (1998).

13. B.S. Kang, D.H. Kim, T.S. Jung, E.K. Jang, Y.Pak, S.C. Shin, D.-S. Park, and Y.-B. Shim, Synthetic. Met., 105, 9 (1999).

14. T.S. Jung, J.H. Kim, E.K. Jang, D.H. Kim, Y.-B. Shim, B. Park, and S.C. Shin, J. Organomet. Chem., 599, 232 (2000).

15. D.H. Kim, D.-S. Park, Y.-B. Shim, and S.C. Shin, $J$. Organomet. Chem., 608, 133 (2000).

16. D.H. Kim, J.-H. Kim, T.H. Kim, D.M. Kang, Y.H. Kim, Y.-B. Shim, and S.C. Shin, Chem. Mater., 15, 825 (2003).

17. T.-Y. Lee, Y.-B. Shim, and S.C. Shin, Synthetic. Met., 126, 105 (2002).

18. H. Seol, D.M. Kang, S.C. Shin, and Y.-B. Shim, Synthetic. Met., 156, 65 (2006).

19. Y.H. Kim, J. Hwang, J.I. Son, and Y.-B. Shim, Synthetic. Met., 160, 413 (2010).

20. J.I. Son, J. Hwang, S.-H. Jin, and Y.-B. Shim, J. Electroanal. Chem., 628, 16 (2009).

21. M.A. Rahman, P. Kumar, D.-S. Park, and Y.-B. Shim, 
Sensors, 8, 118 (2008).

22. Y.-B. Shim, D.E. siilwell, and S.-M. Park, Electroanal., 3, 31 (1991).

23. Y.-B. Shim, and J.-H. Park, J. Electrochem. Soc., 147, 381 (2000).

24. M.A. Rahman, M.-S. Won, N.-H. Kwon, J.-H. Yoon, D.S. Park, and Y.-B. Shim, Anal. Chem., 80, 5307 (2008).

25. M.-S. Won, J.-H. Yoon, and Y.-B. Shim, Electroanal., 17, 1952 (2005).

26. H. Park, T.-G. Kwon, D.-S. Park, and Y.-B. Shim, Bull. Korean Chem. Soc., 27, 1763 (2006).

27. M. Boopathi, M.-S. Won, Y.H. Kim, S.C. Shin, and Y.-B. Shim, J. Electrochem. Soc., 149, E265 (2002).

28. T.-Y. Lee, and Y.-B. Shim, Anal. Chem., 73, 5629 (2001).

29. M.A. Rahman, M.-S. Won, and Y.-B. Shim, Anal. Chem., 75, 1123 (2003).

30. H. Seol, S.C. Shin, and Y.-B. Shim, Electroanal., 16, 2051 (2004).

31. F. Darain, S.-U. Park, and Y.-B. Shim, Biosens. Bioelectron., 18, 773 (2003).

32. F. Darain, D.-S. Park, J.-S. Park, and Y.-B. Shim, Biosens. Bioelectron., 19, 1245 (2004)

33. F. Darain, D.-S. Park, J.-S. Park, S.-C. Chang, and Y.-B. Shim, Biosens. Bioelectron., 20, 1780 (2005).

34. M.A. Rahman, M.J.A. Shiddiky, J.-S. Park, and Y.-B. Shim, Biosens. Bioelectron., 22, 2464 (2007).

35. F. Darain, C. Ban, and Y.-B. Shim, 'Biosens. Bioelectron., 20, 857 (2004).

36. Y.-T. Kong, M. Boopathi, and Y.-B. Shim, Biosens. Bioelectron., 19, 227 (2003).

37. M.A. Rahman, D.-S. Park, and Y.-B. Shim, Biosens. Bioelectron., 19, 1565 (2004).

38. M.A. Rahman, M.-S. Won, and Y.-B. Shim, Biosens. Bioelectron., 212, 57 (2005).

39. C. Ban, S. Chung, D.-S. Park, and Y.-B. Shim, Nucleic. Acids. Res., 32, e110-p8 (2004).

40. H.-J. Kim, K.-S. Lee, M.-S. Won, Y.-B. Shim, Langmuir, 24, 1087, (2008)

41. N.-H. Kwon, M.A. Rahman, M.-S. Won, and Y.-B. Shim, Anal. Chem., 78, 52 (2006).

42. M.A. Rahman, D.-S. Park, S.-C. Chang, C.J. McNeil, and Y.-B. Shim, Biosens. Bioelectron., 21, 1116 (2006).

43. F. Darain, J.-S. Park, H. Akutsu, and Y.-B. Shim, Biosens. Bioelectron., 23, 161 (2007).

44. W.C.A. Koh, M.A. Rahman, E.S. Choe, D.K. Lee, and Y.-B. Shim, Biosens. Bioelectron., 23, 1374 (2008).

45. M.A. Rahman, N.-H. Kwon, M.-S. Won, E.S. Choe, and Y.-B. Shim, Anal. Chem., 77, 4854 (2005).

46. M.A. Rahman, M.-S. Won, and Y.-B. Shim, Electroanal., 19, 631 (2007).

47. A.A. Abdelwahab, H.-M. Lee, and Y.-B. Shim, Anal. Chim. Acta., 650, 247 (2009).

48. A.A. Abdelwahab, M.-S. Won, and Y.B. Shim, Electroanal., 22, 21 (2010).

49. D. Das, D.-M. Kim, D.-S. Park, Y.-B. Shim, Electroanal., 23, $2036(2011)$
50. A.A. Abdelwahab, D.-M. Kim, N. M. Halappa, Y.-B. Shim, Electroanal., 25, 1178 (2011).

51. M.J.A. Shiddiky, D.-S. Park, and Y.-B. Shim, Electrophoresis., 26, 4656 (2005).

52. M.J.A. Shiddiky, M.A. Rahman, J.S. Park, and Y.-B. Shim, Electrophoresis., 27, 2951 (2006).

53. J.I. Son, A. Kim, H.-B. Noh, H.J. Lee, Y.-B. Shim, and K.H. Park, Bull. Korean Chem. Soc., 33, 319 (2012).

54. M. Boopathi, M.-S. Won, and Y.-B. Shim, Anal. Chim. Acta., 512, 191 (2004).

55. M.A. Rahman, K.-S. Lee, D.-S. Park, M.-S. Won, and Y.B. Shim, Biosens. Bioelectron , 23, 857 (2008).

56. W.C.A. Koh, J.I. Son, E.S. Choe, and Y.-B. Shim, Anal. Chem., 82, 10075 (2010).

57. D.-M. Kim, M.-Y. Kim, S.S. Reddy, J. Cho, C.-H. Cho, S. Jung, and Y.-B. Shim, Anal. Chem., 85, 11643 (2013).

58. M.A. Rahman, J.I. Son, M.-S. Won, and Y.-B. Shim, Anal. Chem., 81, 6604 (2009).

59. H.-B. Noh, M.A. Rahman, J.E. Yang, and Y.-B. Shim, Biosens. Bioelectron, 26, 4429 (2011).

60. D.-M. Kim, M.A. Rahman, M.H. Do, C. Ban, and Y.-B. Shim, Biosens. Bioelectron., 25, 1781 (2010).

61. P. Chandra, W.C.A. Koh, H.-B. Noh, and Y.-B. Shim, Biosens. Bioelectron., 32, 278 (2012).

62. Y. Zhu, J.I. Son, and Y.-B. Shim, Biosens. Bioelectron., 26, 1002 (2010).

63. Y. Zhu, W.C.A. Koh, and Y.-B. Shim, Electroanal., 22, $2908(2010)$.

64. S. Lee, K.-M. Song, W. Jeon, H. Jo, Y.-B. Shim, and C. Ban, Biosens. Bioelectron., 35, 291 (2012).

65. Y. Zhu, P. Chandra, K.-M. Song, C. Ban, and Y.-B. Shim, Biosens. Bioelectron., 36, 29 (2012).

66. Y. Zhu, P. Chandra, C. Ban, and Y.-B. Shim, Electroanal., 24, 1057 (2012).

67. Y. Zhu, P. Chandra, and Y.-B. Shim, Anal. Chem., 85, 1058 (2013).

68. P. Chandra, H.-B. Noh, M.-S. Won, and Y.-B. Shim, Biosens. Bioelectron., 26, 4442 (2011).

69. K. Singh, M.A. Rahman, J.I. Son, K.C. Kim, and Y.-B. Shim, Biosens. Bioelectron., 23, 1595 (2008).

70. D.-M. Kim, H.-B. Noh, D.-S. Park, S.-H. Ryu, J.S. Koo, and Y.-B. Shim, Biosens. Bioelectron., 25, 456 (2009).

71. W.C.A. Koh, P. Chandra, D.-M. Kim, and Y.-B. Shim, Anal. Chem., 83, 6177 (2011).

72. K.-S. Lee, M.-S. Won, H.-B. Noh, and Y.-B. Shim, Biomaterials, 31, 7827 (2010).

73. A.A. Abdelwahab, W.C.A. Koh, H.-B. Noh, and Y.-B. Shim, Biosens. Bioelectron., 26, 1080 (2010).

74. H.-B. Noh, P. Chandra, J.O. Moon, and Y.-B. Shim, Biomaterials, 33, 2600 (2012).

75. M.A. Rahman, A. Kothalam, E.S. Choe, M.-S. Won, and Y.-B. Shim, Anal. Chem., 84, 6654 (2012).

76. P. Chandra, N.X. Son, H.-B. Noh, R.N. Goyal, and Y.-B. Shim, Biosens. Bioelectron., 39, 139 (2013).

77. P. Chandra, H.-B. Noh, and Y.-B. Shim, Chem. Commun., 49, 1900 (2013). 
78. M.J.A. Shiddiky, M.A. Rahman, and Y.-B. Shim, Anal. Chem., 79, 6886 (2007).

79. M.J.A. Shiddiky, M.A. Rahman, C.S. Cheol, and Y.-B. Shim, Anal. Biochem., 379, 170 (2008).

80. M.A. Rahman, H.-B. Noh, and Y.-B. Shim, Anal. Chem., 80, 8020 (2008).

81. M.M. Rahman, M.J.A. Shiddiky, M.A. Rahman, and Y.B. Shim, Anal. Biochem., 384, 159 (2009).

82. H.-B. Noh, P. Kumar, T.K. Biswas, D.-S. Kim, and Y.-B. Shim, Electroanal., 22, 632 (2010).

83. D.-M. Kim, Y.-B. Shim, Anal. Chem., 85, 6536 (2013).

84. P. Chandra, S.A. Zaidi, H.-B. Noh, and Y.-B. Shim, Biosens. Bioelectron., 28, 326 (2011).

85. S.-Y. Won, P. Chandra, S.H. Tak, and Y.-B. Shim,
Biosens. Bioelectron., 39, 204 (2013).

86. B. ORegan, M. Grätzel, Nature 353, 737 (1991).

87. J.-H. Yoon, D.-M. Kim, S.-S. Yoon, M.-S. Won, and Y.B. Shim, J. Power. Sources., 196, 8874 (2011).

88. D.-M. Kim, J.-H. Yoon, M.-S. Won, and Y.-B. Shim, Electrochim. Acta., 67, 201 (2012).

89. D.-M. Kim, K.-B. Shim, J.I. Son, S.S. Reddy, Y.-B. Shim, Electrochim. Acta., 104, 322 (2013).

90. J. Hwang, J.I. Son, and Y.-B. Shim, Sol. Energ. Mat. Sol. C., 94, 1286 (2010).

91. H.-B. Noh, M.-S. Won, J. Hwang, N.-H. Kwon, S.C. Shin, and Y.-B. Shim, Biosens. Bioelectron. 25, 1735 (2010). 